\title{
Placement decisions of families co-residing with an adult relative with an intellectual disability
}

\begin{abstract}
Background: No studies exist which explore placement behaviours of families of adults with intellectual disabilities.

Methods: A prospective design was adopted to examine changes in placement decision of 75 family carers over a 12-month period. Factors associated with changes were also examined.

Results: Over 12 months, 30 families moved closer to considering an out-ofhome placement. Of these 14 had placed their relative out-of-home. Active coping strategies were significantly associated with an increased likelihood of continued home care.

Conclusion: Whilst the results were similar to studies with children with ID/ASD, a move out-of-home occurred more quickly for adults. This may reflect current social policy and societal attitudes where a move out-of-home is more normative for adults with ID. The lack of association with all but one carer/care recipient factors suggest that changes in placement tendencies for adults may differ from that of children.
\end{abstract}

Keywords: Family carers, adults, intellectual disability, placement decisions 


\section{FAMILIES’ PLACEMENT DECISIONS FOR ADULTS WITH ID}

A growing body of empirical evidence exists that explores factors associated with the relinquishment of care of a relative with an intellectual disability (ID) by family carers (Chiu \& Hung, 2006; McConkey, Kelly, Mannan, \& Graig, 2011; McConnell, Savage, Breitkreuz, \& Sobsey, 2016; Nankervis, Rosewarne, \& Vassos, 2011; Taggart, Truesdale-Kennedy, Ryan, \& McConkey, 2012). Factors include those related to carers and families, and relatives with an ID. Nankervis and Rosewarne (2011) found that factors associated with adult relatives' characteristics included the individual having higher support needs, challenging behaviours which had worsened with age, together with care provision becoming more difficult as a relative had become physically bigger and heavier in adulthood. Family carer characteristics included caregiver stress, exhaustion, depression, lone parent status and caregivers own ageing, ill health or even death. Families also reported resorting to relinquishment of care as a strategy for gaining an out-of-home placement. Families' desire for a 'normal life' for both themselves and their adult relative was another factor. Much of the same evidence was reported by Grey, Griffith, Totsika and Hastings (2015) when exploring families' experiences of seeking out-of-home accommodation for their adult relative. Increasing care demands co-occur with parents getting older and experiencing a decline in their own physical health which can served to increased motivation to seek an out-of-home placement (Grey et al., 2015). McConnoll et al. (2016) found age to be a predictor of placement propensity, with families whose children were between the ages of 13-18 being more likely to pursue an out-of-home placement, than those with younger children. Availability of appropriate resources such as flexible work hours was associated with sustained family care. 


\section{FAMILIES’ PLACEMENT DECISIONS FOR ADULTS WITH ID}

Barrier to successful out-of-home transition included the lack of available housing and continuous offers of inappropriate placements which potentially put relatives at risk. Examples include housing situated in areas deemed unsafe by the police and a female relative being offered a placement shared with an older male (Grey et al., 2015). Universal Credit, a means tested benefit paid directly to people on low income, was introduced into the UK as part of the Welfare Reforms Act (2013) to consolidate a number of separate benefits into one payment. This has resulted in the abolishment of the benefits including the Severe Disability Premium (SDP). This has been estimated to leave those previously in receipt of this payment with a deficit of approximately $£ 1500$ per annum (Royston \& Rodrigues, 2012). Universal Credit has also resulted in landlords, who would previously have received direct payment of rent from local government housing departments, being reluctant to offer tenancies to receipients due to soaring rent arrears (Simcock, 2018). With the dearth of available housing to adults with ID (Mencap, 2012), relinquishment of care is likely to put pressure on limited places. It would therefore seem expedient to explore methods of predicting potential demand upon already scarce services.

Over two decades ago, Blacher (1990) developed a theory to explain the processes which families pass through prior to moving or 'placing' their child with ID out-of-home. Blacher proposed that placement decisions do not occur as one-off discrete events but are cognitive processes characterised by six sequential hierarchical decision making and behavioural stages (see table 2 and measures section). These stages are also reflective of families' ethos towards care provision which intrinsitcally influence these behaviours. Adopting a prospective design to test this theory, Blacher examined the ongoing cognitive and behavioural processes of 84 families of children aged 3 to 8 years with severe ID. Results showed little or no change for families who 


\section{FAMILIES’ PLACEMENT DECISIONS FOR ADULTS WITH ID}

were initially at the earlier stages of placement thinking (stages 1-3 on the Placement Tendency Index, PTI) over the three-year study period. However, strong relationships were found between families who had initially reached further stages of the placement process (stage 4 and 5) and the subsequent occurrence of an out-of-home placement. Blacher called these latter stages "the point of no return", due to the seemingly inevitable move towards a placement once families had reached these stages of decision making.

Support for Blacher's placement tendency theory and the predictive properties of the PTI, come from both retrospective (Blacher \& Baker, 1994; Llewellyn, Dunn, Fante, Turnbull, \& Grace, 1999) and prospective, longitudinal studies of families with young children (Blacher \& Hanneman, 1993; Hanneman \& Blacher; 1998; Llewellyn et al., 2003; Llewellyn, McConnell, Thompson, \& Whybrow, 2005) and adolescents/young adults (McIntyre, Blacher, \& Baker, 2002) with severe or profound ID and children with autistic spectrum disorder (ASD)/pervasive developmental disorders (Perry \& Black, 2006).

Whilst previous studies exploring families' placement tendencies have been extensive in their breadth and depth, to our knowledge, no studies have explored the dynamics of placement tendencies and factors associated with changes in these tendencies of families of adults with a wide spectrum of support needs (see Table 1). Whilst McIntyre et al. (2002) explored placement tendencies of parents of young adults with ID, they focused on the period between adolescence and adulthood (16 and 25 year of age). Many of their study sample were still attending educational institutions. Adolescence is characterised by issues specific to this developmental period such as biological change and a striving for greater autonomy (Crockett \& Crouter, 2014). Therefore factors affecting placement decisions of families of older 


\section{FAMILIES’ PLACEMENT DECISIONS FOR ADULTS WITH ID}

adults may differ especially given the differences in the contemporary social and policy context within which care is provided in Western societies. Families and adults with ID are now afforded greater aspirations towards independence which, in principle, are increasingly gaining normative status (Department of Health, 2001, 2009; United Nations, 2006; Welsh Assembly Government, 2007). The placement of a child either with or without a disability out-of-home is considered less usual and is often prompted by adverse family circumstances (Ehrle \& Green, 2002; Slayter \& Springer, 2011). Finally, previous studies exploring the predictive properties of the PTI have all taken place outside of the UK, with much of the research occurring sometime ago. The aim of this study is therefore, to

a) examine changes in the placement tendencies of families of adults with ID over a 12-month period using the PTI in a contemporary and novel context.

b) identify whether earlier social, demographic, or psychological characteristics of the family or the adult with ID are associated with changes on the PTI.

\section{Method}

A prospective design was adopted to explore placement decisions of family carers who co-reside with an adult relative with ID over a 12-month period. It follows up on an original cross-sectional study examining the health and well-being of family carers of adults with ID (Grey, Totsika, \& Hastings, 2018). Participants from the original study were asked to indicate their agreement to be contacted by researchers for potential inclusion in the follow up study 12 months subsequent to completion of a batch of questionnaires at Time 1. Placement Tendency scores were measured at Time 1 and Time 2. The criteria for inclusion in this study required participants to be English or Welsh speaking and the main carer for an adult relative aged 18 years or 


\section{FAMILIES' PLACEMENT DECISIONS FOR ADULTS WITH ID}

over who was, at Time 1 living in the family home.

\section{Participants}

All measures included were chosen for their ease of completion and suitability in an online or postal survey. At Time 1, participants completed a demographic questionnaire specifically designed for the current study, together with a batch of other measures which included the PTI (see measures section).

Carer characteristics. Of 110 family carers at Time 1, 105 families agree to be contacted at Time 2. The final number of participants who completed and returned PTI questionnaires at Time 2 was $N=75$. Although the majority of carers answered all questions, percentages are shown based on the total number of people who responded to each question. Carers' ages ranged from 36 to 86 years $(M=61.36$ years; $S D=10.15)$. See Table 1 for full demographic information.

Adult relative characteristics. Adult relatives ages ranged from 18-67 years $(M=36.18, S D=11.99)$ with the majority $(61.3 \%)$ being male. Five variables indicated whether adult relatives had additional support needs i.e. 1) 'is able to speak/sign 30 words or more' (reverse scored), 2) 'has visual or hearing impairment', 3) 'is continent during the day time and/or night time' (reverse scored), 4) 'currently has epileptic seizure' and 5) 'needs support at meal times'. A composite support needs variable was created with scores ranging from 0-5, with higher scores representing higher support needs. (See Table 1). 


\section{FAMILIES’ PLACEMENT DECISIONS FOR ADULTS WITH ID}

\section{Measures}

All measures including the PTI were completed at Time 1 of the study. The PTI was the only measure subsequently re-administered at Time 2 for the prospective follow-up study. All predictor variables used in the current study were created from data collected at Time 1 .

Placement tendency of families. The Placement Tendency Index (PTI, Blacher, 1990) is a single item measured on a six-point scale that assesses thoughts and actions regarding out-of-home placement of a relative. Placement tendency decisions are assessed on stages 1 to 5, with 6 indicating an actual move out-of-home has occurred (see Table 2). Theoretcially no family can achieve a higher stage without having first passed through earlier stages. The original wording was changed to reflect a UK context with the word 'placement' being substituted by the word 'accommodation' and stage 6 'we have placed our child' being substituted for 'our son/daughter has moved out of our home'.

Socio-economic position (SEP). The household composition variable was weighted in accordance with the OECD-modified equivalence scale (Office for National Statistics, 2013) to create a new single variable weighted to account for household composition. A second single variable was calculated from the mean of the weekly family household income. This new weekly income variable was then divided by the equivalised household composition variable to create a new single household income variable which has been adjusted to take account of household size and composition

Postal code information was linked to geographical areas for each of the UK countries and used to estimate area deprivation using Indices of Multiple Deprivation. 


\section{FAMILIES’ PLACEMENT DECISIONS FOR ADULTS WITH ID}

A dichotomous variable was created indicating whether carers were living in one of the $20 \%$ most deprived neighbourhoods.

Family resources. The Family Resources Scales (FRS, Dunst \& Leet, 1986, 1987) comprises 30 items rated on a six-point Likert scale, measuring the extent to which resources for families are adequately met (e.g., basic necessities such as food and shelter, and less essential resources such as family holidays). This scale was analysed both as a total score and, separately included as part of the family SEP composite variables, to indicate family hardship. Two of the subscales which indicated material hardship ('necessities and health' and 'physical necessities and shelter') were summed to create a single interval 'material resources' variable with scores ranging from 0 to 60 . The summed scores of the 'material resources' variable were subsequently split at the median (median score $=49$ ), to form a single dichotomous 'hardship' variable indicating to what extent resources were adequately met. Thirty five (46.7\%) carers felt that access to resources were not adequate to meet their families' needs.

A composite variable indicating families' socio-economic position (SEP) was created using five indicators: area deprivation (IMD), hardship, carers' employment status, educational status and income poverty. The SEP composite scores ranged from 0 to 5, with higher scores representing higher SEP.

Carer's health related quality of life (HQoL). Carers' HQoL was measured by the EQ-5D-3L (EuroQol Group, 1990). EQ-5D-3L is a generic measure of HQoL which includes a descriptive system (EQ-5D) and a visual analogue scale (EQ-VAS). The descriptive scale enables participants to self-classify health states along five dimensions (mobility, self-care, usual activities, pain/discomfort and anxiety/depression). The descriptive system is measured at ordinal level with each 
FAMILIES' PLACEMENT DECISIONS FOR ADULTS WITH ID

dimension being at 3 levels, 'no problems', 'some problems' and 'extreme problems'. Higher scores indicate lower levels of health in a particular dimension of health. The descriptive system has the potential of defining a total of 243 health states.

The EQ-VAS is a $20 \mathrm{~cm}$ visual analogue scale on which respondents rate their subjective general health state on the date of completion. The scale ranges from 0 (worst imaginable health state) to 100 (best imaginable health state).

Care recipient's health related quality of life. HQoL of adult relatives was measured by the EQ-5D-3L, Proxy version 2 (EuroQol Group, 1990). This measure is made up of the same two page measure as the self-completed EQ-5D, with both the descriptive and VAS measures included. The proxy version requires 'the proxy' to rate how he/she thinks the care recipient would rate his/her own HQoL.

Family stress. The Questionnaire on Resources and Stress - short form (QRSF: Friedrich, Greenburg \& Crnic, 1983), Parent and Family Problem Sub-scale 7-item version (Griffith et al., 2011) was used. The QRS-F is a self-report questionnaire which measures general stress related to caring for a family member with a disability or chronic illness. The total score for this measure is 7, with higher scores reflecting higher levels of family stress.

Family support. The Family Support Scale (FSS; Dunst, Jenkins, \& Trivette, 1984) is a self-report measure comprising 19-items designed to assess potential sources of support available to family carers and the degree of perceived helpfulness.

Family coping. The Family Crisis Oriented Personal Scale (F-Copes; McCubbin, Olson, \& Larsen, 1981) consists of 30 statements presented on a 5-point Likert scale designed to measure both problem focused and passive coping strategies adopted by families in times of crisis. Variables were summed to create a single 


\section{FAMILIES’ PLACEMENT DECISIONS FOR ADULTS WITH ID}

variable for coping strategies with scores ranging from 30-150. Higher scores indicate more active coping strategies.

Carer distress. The Kessler 6 (K6, Kessler et al., 2002) is a 6-item scale measuring non-specific psychological distress over a past 30 day period. Respondents rate 6-items presented on a 5-point Likert scale scored to reflect how often they experienced negative feelings. The maximum score is 24 , where higher scores indicate greater levels of carer distress. The K6 was also transformed into a dichotomous variable using the score of 13 or above to categorise carers who were at risk of serious mental illness (SMI).

Carer burden. The Zarit Burden Index, 12-items (ZBI; Bédard, Molloy, Squire, Dubois, Lever, \& O’Donnell, 2001). The abridged 12-item, self-report index has been developed from the original 29-item scale (Zarit, Reever, \& Bach-Peterson, 1980) designed to measure subjective caregiving burden. Each item is rated on a 5point scale. Question 9 ('Do you feel you have lost control of your life since x's condition?') was omitted from the current study, as this related to the onset of a condition in later life such as Alzheimer's disease. The maximum score of the 11 questions was therefore 44, with higher scores indicating higher levels of burden. (See Grey, Totsika, \& Hastings, 2018 for full details of measures).

\section{Procedure}

The study protocol was approved by the Research Ethics and Governance Committee at Bangor University in the UK. Participants were recruited through statutory and voluntary organisations who circulated a recruitment advertisement to their members and service users via email, websites and newsletters. Social media (e.g., Twitter and Facebook, on-line fora) were also used to distribute information about the study. Of the 110 participants at Time 1,105 consented to be followed up 
FAMILIES' PLACEMENT DECISIONS FOR ADULTS WITH ID

12 months later. Seventy five returned the completed PTI which resulted in an overall participant retention rate of $71 \%$.

\section{Results}

To answer the first question of whether changes occurred in families' placement decision between Time 1 and Time 2, an initial examination of scores at both time points was undertaken (Table 2).

Insert Table 2 here

In the 12-month period, families' placement tendency scores did change:

Increases in PTI scores: Thirty families (40\%) showed an increase in scores, indicating a moved closer to considering an out-of-home placement. Twentyfour (almost 32\%) of these families had moved forwards only one step on the PTI. A one step increase in PTI scores resulted in 10 of these families moving their relative out-of-home at Time 2 and seven progressing to the more serious stages of considering out-of-home accommodation for their relative (i.e., stages 4 or stage 5).

In total 14 of the 75 families (almost 19\%) had moved their relative out-ofhome at Time 2 (score 6). Consistent with Blacher's theory, 10 of these families (mentioned above) were at stage 5 of the PTI, the additional family was at stage 4 . Inconsistent with Blacher's theory, three of the 14 families were only in the early stages (1 and 2) of placement thinking at Time 1. Blacher's original placement tendency theory proposes that placement decisions are hierarchical and that theoretically no person could achieve any step on the PTI without having first passed through a previous sequential stage. According to Blacher's theories, families recording lower scores on the PTI would not be expected to have placed their son or 


\section{FAMILIES’ PLACEMENT DECISIONS FOR ADULTS WITH ID}

daughter out-of-home at Time 2. The current findings may, however, be the result of families' responding to a sudden change of circumstances such as a 'crisis' situation where continued home care was no longer feasible (Blacher \& Hanneman, 1993). Crisis placements would explain the absence of planning or preparation prior to a placement occurring (Crettenden \& Wright, 2014). Additionally, an unexpected opportunity for their son or daughter to live more independently may also explain this result (Llewellyn et al., 2003). Whilst these seemingly abrupt placement behaviours do not follow the predicted behavioural patterns of placement tendency theory and may appear to bear little relationship to carers' initial placement intentions as captured by the PTI, Blacher does make the point that the decision to look for out-ofhome accommodation is complex. Initial intentions recorded by families of 'never having thought about out-of-home accommodation', may not necessarily rule out some less tangible thoughts towards placement which have not explicitly been expressed or recorded on the PTI by families.

Decreases in PTI scores: Fourteen families's scores (almost 19\%) decreased, demonstrating a move away from considering an out-of-home placement. Unexpectedly, eight of these families were at the later stages of placement thinking at Time 1. Whilst half of these families had only moved one stage backwards, the other half had moved from stage 4 or 5 to the earlier stages on the Index indicating an extreme decline in placement thinking. Whilst this represents only a small number of families, this is in contrast with Blacher's theory which posits that once families have reached the latter stages of placement thinking (stage 4 and above), a move away from favouring a placement was unlikely. Descriptive data shows that six of these eight families reported high levels of family stress at Time 1 . Whilst we can only speculate as to the reason for this decline in favouring an out-of-home placement 


\section{FAMILIES’ PLACEMENT DECISIONS FOR ADULTS WITH ID}

having only collected predictive data at Time 1, changes in family circumstance during the 12 months may have enabled continued home care. Collecting more predictive data at Time 2 could help with an understanding of these changes in behaviour.

No changes in PTI scores: Of the 75 families taking part in this study, 31 (41\%) demonstrated no change in their PTI scores at Time 2.

To answer the second research question exploring factors associated with changes in families' placement decisions occurring between Times 1 and 2, we created two new dichotomous outcome variables using the PTI scores from Time 1 and Time 2, as below:

1) No change/moved backwards $(N 45,60 \%)$ vs moved forwards $(N 30,40 \%)$ on the PTI.

2) Living at home $(N 61,81.3 \%)$ versus moved out of home $(N 14,18.7 \%)$ at Time 2.

In order to examine independent factors which may increase the likelihood of the observed events occurring (i.e., a move forwards on the PTI, closer to more serious consideration of an out-of-home placement and a move out of home) without the presence of other possible confounding factors, we first regressed the two outcome variables in logistic regression models on single indicators of carer characteristics, adult relatives' characteristics and family characteristics (see Table 1).

The total coping score was the only variable which was significantly associated with relatives remaining at home at Time 2 of the study $(\mathrm{OR}=0.95,(95 \%$ CI $0.91-0.98), p=.01$ ). This indicates that carers who adopt more proactive or problem focused coping strategies were more likely to continue providing home care to their relative at Time 2 . No other predictor variables were significantly associated 


\section{FAMILIES’ PLACEMENT DECISIONS FOR ADULTS WITH ID}

with either outcome variable at Time 2 (Full details of regression analyses can be obtained from lead author). Exploration of these associations in multivariate models was not undertaken due to the lack of significant finding and wide CIs for most of the ORs in univariate analyses.

\section{Discussion}

A prospective design was adopted to examine potential changes in the placement tendencies of family carers of adults with ID over a 12-month period and assess factors associated with these changes. To our knowledge, this is the first study to explore the placement tendencies of family carers of adults with ID. The study is also the first to explore the predictive properties of the PTI in any population in a contemporary policy context in the UK.

Descriptive data showed that changes in the placement tendencies of families' of adults with ID, on the whole, showed similarities in patterns found in previous studies with children with severe ID and/or autism conducted in North America (Blacher, 1990; Blacher \& Hanneman, 1993; Hanneman \& Blacher, 1998; McIntyre et al., 2002; Perry \& Black, 2006) and Australia (Llewellyn et al., 2005). Consistent with previous evidence and lending some support to the predictive capacity of the PTI, the majority of families who had placed their relative out-of-home by Time 2 were at the later stages of placement thinking at Time 1 . The small inconsistencies found for three families whose relative had moved out-of-home at T2 although initially in the earliest stages of placement thinking at Time 1, were consistent with the occurrence of a 'crisis' (Blacher \& Hanneman, 1993; Crettenden \& Wright, 2014; Perry \& Black, 2006) or 'opportunity’ placement (Llewellyn et al., 2003). The accelerated placement may, therefore, have occurred due to unforeseen circumstances (e.g. carers' inability to continue care) or the sudden availability of out-of-home 


\section{FAMILIES’ PLACEMENT DECISIONS FOR ADULTS WITH ID}

accommodation arising, as opposed to planned actions or previous placement intentions. Whilst obvious caution is needed in interpreting the results for such a small number of families, it may, however, suggest that not all placement decisions for adults occur as the result of families' passing through sequential behavioural stages. Factors influencing accelerated placement may fail to be picked up when administering the PTI over a time period of 12 months. Also, the placement tendency model may not necessarily account for changes in external factors (e.g. the availability of suitable out-of-home housing) that may accelerate or change the course of parental behaviour.

A lack of appropriate accommodation for adults with ID and/or families finding some form of adaption which enables continue home care (Blacher \& Hanneman, 1993; Grey et al., 2018; McConnoll et al., 2016) may also explain this declining pattern of placement seeking behaviours subsequent to reaching the enquiry stages (Department of Health, 2011; Grey et al., 2015; 2012; Perry \& Black, 2006). Inter-family disagreement or ambivalence towards an out-of-home placement for a relative has also been found to influence this changing pattern of behaviour, a factor which was not measured in the current research (Blacher \& Hanneman, 1993). Future research should, therefore, consider the inclusion of whole family attitudes towards placement as an influence on subsequent placement behaviours.

The current study showed a more rapid rate of out-of-home placement for adults with ID than demonstrated in previous longitudinal studies of children with severe ID (Blacher, 1990, Blacher \& Hanneman, 1993; Hanneman, \& Blacher, 1998). Perry and Black (2006) found a similar discrepancy in rate of placement of a sample which included a small number of young adults with ASD. This discrepancy may be reflective of differences in current social policy, care and societal attitudes to placing 


\section{FAMILIES’ PLACEMENT DECISIONS FOR ADULTS WITH ID}

an adult as opposed to a child, out-of-home (United Nation, 2006; Welsh Assembly Government, 2007). Whilst the dearth of appropriate housing creates a barrier to successful out-of-home placements (Grey et al., 2015; Mencap, 2012), nevertheless, the right of adults with an ID to live independently remains an aspiration (Department of Health, 2001, 2009; United Nations, 2006). The placement of a child out-of-home, even those with disabilities, is a more traumatic experience, often prompted by adverse family circumstances (Ehrle \& Green, 2002; Slayter \& Springer, 2011).

An exploration of unadjusted ORs as predictors of the likelihood of families moving closer to a placement at Time 2 , revealed only coping as a significant predictor of families favouring continued home care. This finding is consistent with previous evidence that suggests carers who are better adapted to coping with providing care for a relative with ID, are less likely to favour out-of-home placement (Grey et al., 2018; Hanneman \& Blacher, 1998). Coping strategies have consistently been associated with better adjustment to the caregiving role, which, in turn buffers negative impacts upon carers' and family well-being (Grey et al., 2018; Llewellyn, McConnell, Gething, Cant, \& Kendig, 2010; Peer \& Hillman, 2012). The lack of significant associations for the remaining predictors may be a result of the small sample size reducing measurement precision and inflating some of the CIs. Recruitment of larger samples may go some way to addressing these problems.

\section{Implications for policy and practice}

Whilst there are obvious limitations on the generalisability of the findings of the present study due, in part to the small sample size and self-selected nature of participants, gaining a better understanding of the patterns of placement behaviours of families' of adults with ID and early indicators of the number of families who may be 


\section{FAMILIES’ PLACEMENT DECISIONS FOR ADULTS WITH ID}

moving closer to seeking out-of-home accommodation, could have the potential to assist with future service planning for both housing and support service providers. This is of particular importance with the current lack suitable accommodation together with the challenges posed by the re-organisation of the benefit system in the UK. More large scale, longitudinal research is, however, needed exploring variables which better predict families' decisions to relinquish care of a relative with ID. Additionally, the security of tenancy agreements for adults with ID should also be explored.

Whilst we still do not know what factors are associated with families being more or less likely to place their adult relative out-of-home, the suggested association of carer adaption and continued home care highlight the need to make widely available family support services that can support families in their ongoing role as carers. This is especially relevant due to the current lack of appropriate accommodation for adults with ID and in the light of shrinking social care budgets. 
FAMILIES' PLACEMENT DECISIONS FOR ADULTS WITH ID

\section{References}

Bédard, M., Molloy, D. W., Squire, L., Dubois, S., Lever, J. A., \& O’Donnell, M. (2001). The Zarit Burden Interview: A new short version and screening version. The Gerontologist, 41, 652-657. doi: 10.1093/geront/41.5.652

Blacher, J. (1990). Assessing placement tendency in families with children who have severe handicaps. Research in Developmental Disabilities, 11(4), 349-359. doi: $10.1016 /$ 0891-4222(90)90022-Z

Blacher, J., \& Baker, B. L. (1994). Out-of-home placement for children with retardation: Family decision making and satisfaction. Family Relations, 10-15.

Blacher, J., \& Hanneman, R. (1993). Out-of-home placement of children and adolescents with severe handicaps: behavioral intentions and behavior. Research in Developmental Disabilities, 14(2), 145-160. doi: 10.1016/08914222(93)90017-E

Chiu, M. Y. L., \& Hung, R. C. H. (2006). Decision-making of Chinese caregivers of adults out-of-home placement. Journal of Intellectual Disability Research, 50(9), 678-689. doi: 10.1111/j.1365-2788.2006.00826.x

Crockett, L. J., \& Crouter, A. C. (Eds.). (2014). Pathways through adolescence: Individual development in relation to social contexts. Psychology Press.

Department of Communities and Local Government (2011). English IMD 2010 data. Available from: www.communities.gov.uk/publications/corporate/statistics/ indices 2010

Department of Health (2001). Valuing People: A New Strategy for Learning Disability for the 21st Century: Department of Health, London 
FAMILIES' PLACEMENT DECISIONS FOR ADULTS WITH ID

Department of Health (2009). Valuing People Now: A New Three-Year Strategy for People with Learning Disabilities. The Stationery Office London

Department of Health (2011). Illustrative cost models in learning disabilities social care provision. Healthcare market intelligence, Laing \& Buisson, London

Dunst, C. J., Jenkins, V., \& Trivette, C. M. (1984). 'The Family Support Scale: Reliability and Validity'. Journal of Individual, Family and Community Wellness, 1, 45-52

Dunst, C. J., \& Leet, H. E. (1986). Family Resources Scale, FRS. Cambridge, MA: Brookline Books

Dunst, C. J., \& Leet, H. E. (1987). Measuring the adequacy of resources in households with young children. Child: Care, Health and Development, 13, $111-125$.

EuroQol Group. EuroQol. A new facility for the measurement of health-related quality of life. Health Policy 1990;16:199-208.

Fredrich, W. N., Greenburg, M. T., \& Crnic, K. (1983). A short form of the questionnaire on resources and stress. American Journal of Mental Deficiency, $1,41-48$

Grey, J. M., Griffith, G. M., Totsika, V., \& Hastings, R. P. (2015). Families' experiences of seeking out-of-home accommodation for their adult child with an intellectual disability. Journal of Policy and Practice in Intellectual Disabilities, 12(1), 47-57. doi: 10.1111/jppi.12106

Grey, J. M., Totsika, V., \& Hastings, R. P. (2018). Physical and psychological health of family carers co-residing with an adult relative with an intellectual disability. Journal of Applied Research in Intellectual Disabilities, 31, 191202. doi: $10.1111 /$ jar. 12353 


\section{FAMILIES’ PLACEMENT DECISIONS FOR ADULTS WITH ID}

Griffith, G.M., Hastings, R.P., Oliver, C., Howlin, P., Moss, J., Petty, J., \& Tunnicliffe, P. (2011). Psychological distress and well-being in mothers and fathers of children with Angelman, Cornelia de Lange and Cri du Chat Syndromes. Journal of IntellectualDisability Research, 55, 397-411. doi: 10.1111/j.1365-2788.2011.01386.x

Hanneman, R., \& Blacher, J. (1998). Predicting placement in families who have children with severe handicaps: A longitudinal analysis. American Journal on Mental Retardation, 102(4), 392-408

Kessler, R. C., Andrews, G., Colpe, L. J., Hiripi, E., Mroczek, D. K., Normand, S.-L. T., Walters, E. E., \& Zaslavsky, A. (2002). Short screening scales to monitor population prevalences and trends in non-specific psychological distress. Psychological Medicine, 32, 959-976. doi: http://dx.doi.org/10.1017/S0033291702006074

Kessler, R. C., Barker, P. R., Colpe, L. J., Epstein, J. F., Gfroerer, J. C., Hiripi, E., Howes, M. J, Normand, S-L. T., Manderscheid, R. W., Walters, E. E., \& Zaslavsky, A. M. (2003). Screening for serious mental illness in the general population Archives of General Psychiatry. 60(2), 184-189. doi 10.1001/archpsyc.60.2.184

Llewellyn, G., Dunn, P., Fante, M., Turnbull, L., \& Grace, R. (1999). Family factors influencing out-of-home placement decisions. Journal of Intellectual Disability Research, 43(3), 219-233. doi: 10.1046/ j.1365-2788.1999.00189.x

Llewellyn, G., McConnell, D., Gething, L., Cant, R., \& Kendig, H. (2010). Health status and coping strategies among older parent-carers of adults with intellectual disabilities in an Australian sample. Research in Developmental Disabilities, 31, 1176-1186. doi:_10.1016/j.ridd.2010.08.003 


\section{FAMILIES’ PLACEMENT DECISIONS FOR ADULTS WITH ID}

Llewellyn G., McConnell, D., Thompson, K., \& Whybow, S. (2005). Out-of-home placement of school-aged children with disabilities and high support needs. Journal of Applied Research in Intellectual Disabilities, 18(1), 1-6. doi: 10.1111/j.1468-3148.2004.00201.x

Llewellyn, G., Thompson, K., Whybrow, S., McConnell, D., Bratel, J., Coles, D., \& Wearing, C. (2003). Supporting families: Family well-being and children with disabilities. Sydney, Australia, School of Occupation and Leisure Sciences, University of Sydney.

McConkey, R., Kelly, F., Mannan, H., \& Craig, S. (2011). Moving from family care to residential and supported accommodation: National, longitudinal study of people with intellectual disabilities. American Association on Intellectual and Developmental Disabilities, 116(4), 305-314. doi:

http://dx.doi.org/10.1352/1944-7558-116.4.305

McConnell, D., Savage, A., Breitkreuz, R., \& Sobsey, D. (2016). Sustainable family care for children with disabilities. Journal of child and family studies, 25(2), $530-544$.

McCubbin, H. I., Olson, D., \& Larsen, A. (1981). Family crisis oriented personal scales (F-COPES). In H.I. McCubbin, A.I., Thompson, \& M.A. McCubbin, H.A. (Eds.), Family assessment: Resiliency, coping \& adaptation: Inventories for research and practice (455-507). Madison, WI: University of Wisconsin System.

McCubbin, H. I., Olson, D. H., Larsen, A. S., Corcoran, K., \& Fischer, J. (2000). Family crisis orientated personal evaluation scales [F COPES] $(1987,1991)$. Measures for clinical practice: A sourcebook. 3rd Ed. (2 vols.) NY, Free Pr., $1,294-297$ 


\section{FAMILIES’ PLACEMENT DECISIONS FOR ADULTS WITH ID}

McCubbin, H. I., \& Patterson, J. M. (1983). The family stress process: The double ABCX model of family adjustment and adaptation. Marriage and Family Review 6, 7-37. doi: 10.1300/J002v06n01_02

McIntyre, L. L., Blacher, J., \& Baker, B. L. (2002). Behaviour/mental health problems in young adults with intellectual disability: the impact on families. Journal of Intellectual Disability Research, 46(3), 239-249. doi:

10.1046/j.1365-2788.2002.00371.x

Mencap (2012). Housing for people with a learning disability.

Nankervis, K. L., Rosewarne, A. C., \& Vassos, M. (2011). Respite and parental relinquishment of care: A comprehensive review of the available literature. Journal of Policy and Practice in Intellectual Disabilties, 8(3), 150-162. doi: $10.1111 / \mathrm{j} .1741-1130.2011 .00305 . \mathrm{x}$

Northern Ireland Statistics and Research Agency (2010). Northern Irish MDM 2010 data. Available from: www.nisra.gov.uk/deprivation/nimdm_2010.htm Office for National Statistics (2013), Chapter 3, Equivalised income, Retrieved May 5, 2014, from www.ons.gov.uk/ons/dcp171776_337345.pdf Office for National Statistics (2013), Annual Survey of Hours and Earnings, 2013 Provisional Results. Retrieved July 22, 2014 from http://www.ons.gov.uk/ons/dcp171778_335027.pdf

Peer, J. W., \& Hillman, S. B. (2012). The mediating impact of coping style on stress perception for parents of individuals with intellectual disabilities. Journal of Intellectual Disabilities, 16(1), 45-59. doi: 10.1177/1744629512440783

Perry, A., \& Black, A. (2006). A prospective study of out-of-home placement tendency in families of children with autism. Le journal sur les handicaps $d u$ développement, 47 


\section{FAMILIES’ PLACEMENT DECISIONS FOR ADULTS WITH ID}

Royston, S., \& Rodrigues, L. (2012). Holes in the safety net: The Impact of Universal Credit on Disabled People and their families. London: The Children's Society.

Scottish Government (2012). Scottish IMD 2012 data. Available from

http://simd.scotland.gov.uk/publication-2012/

Simcock, T.J., (2018). Investigating the effect of Welfare Reform on Private Renting. Manchester: UK. Residential Landlords Association. Retrieved from: https://research.rla.org.uk/wpcontent/uploads/investigating-effect-welfarereform-private-renting.pdf

Slayter, E., \& Springer, C. (2011). Child welfare-involved youth with intellectual disabilities: Pathways into and placements in foster care. Intellectual and developmental disabilities, 49(1), 1-13. DOI: 10.1352/1934-9556-49.1.1

Taggart, L., Truesdale-Kennedy, M., Ryan, A., \& McConkey, R. (2012). Examining the support needs of aging family carers in developing future plans for a relative with an intellectual disability. Journal of Intellectual Disabilities, 16(3), 217-234. doi: 10.1177/1744629512456465

United Nations (2006) Convention on the rights of persons with a disability, 2006. http://www.un.org/disabilities/documents/convention/convoptprot-e.pdf (downloaded 03rd January 2015)

Welsh Assembly Government (2007). Statement on policy and practice for adults with a learning disability.

Welsh Assembly Government (2011). Welsh IMD 2011 data. Available from: https://statswales.wales.gov.uk/Catalogue/Community-Safety-and-SocialInclusion/Welsh-Index-of-Multiple-Deprivation/WIMD-2011 


\section{FAMILIES’ PLACEMENT DECISIONS FOR ADULTS WITH ID}

Zarit, S.H., Reever, K.E., \& Bach-Peterson, J. (1980). Relatives of the impaired elderly: correlates of feelings of burden. Gerontologist, 20(6), 649-55.doi: 10.1093/geront/20.6.649 
Table 1 Demographic characteristics for participating carers and their adult relatives with ID

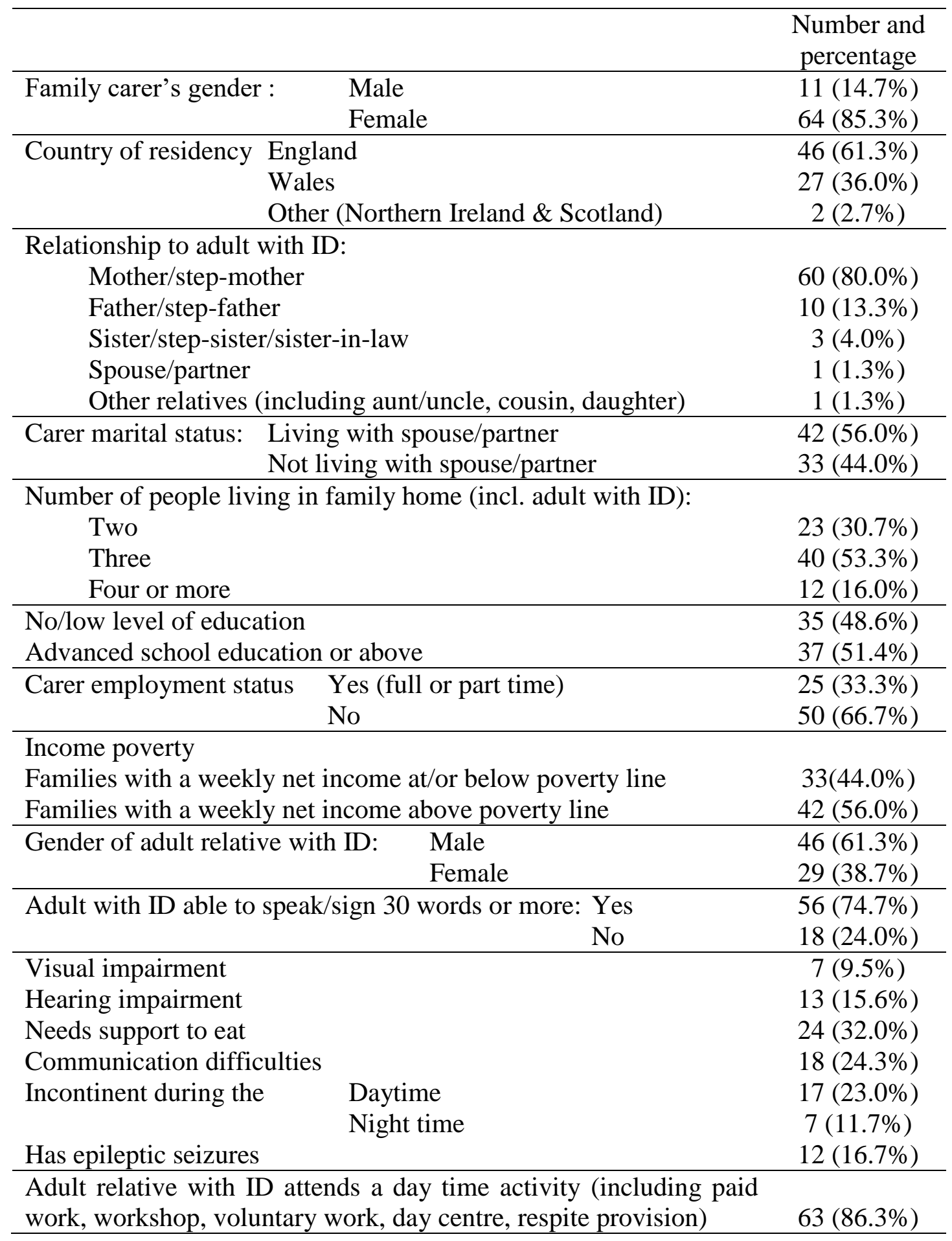


FAMILIES' PLACEMENT DECISIONS FOR ADULTS WITH ID

Table 2: Overall placement tendency scores for participants at Times 1 and 2.

\begin{tabular}{|c|c|c|c|}
\hline & Placement Tendency Index & Time 1 & Time 2 \\
\hline 1) & No, we have never thought about it & $11(14.7 \%)$ & $12(16.0 \%)$ \\
\hline 2) & Occasionally we have given it a thought & $20(26.7 \%)$ & $14(18.7 \%)$ \\
\hline 3) & $\begin{array}{l}\text { Yes, we have thought a lot about it, but we } \\
\text { have done nothing about it }\end{array}$ & $10(13.3 \%)$ & $9(12.0 \%)$ \\
\hline 4) & We have thought about it and made enquiries & $16(21.3 \%)$ & $20(26.7 \%)$ \\
\hline 5) & $\begin{array}{l}\text { We have started to put into action the process } \\
\text { of finding accommodation }\end{array}$ & $18(24.0 \%)$ & $6(8.0 \%)$ \\
\hline 6) & Our son/daughter has moved out of our home & - & $14(18.7 \%)$ \\
\hline
\end{tabular}

